Number (percentage) of people previously known and newly identified with clinical abnormalities in population of 528 people aged 85 years and their contact with general practitioner in year before study

\begin{tabular}{|c|c|c|c|c|}
\hline \multirow[b]{2}{*}{ Clinical abnormality } & \multicolumn{2}{|c|}{ Abnormality } & \multicolumn{2}{|c|}{ No GP contact } \\
\hline & Known & Newly identified & Known & Newly identified \\
\hline Anaemia & $38(24)$ & $118^{\star}(76)$ & $0 / 38(0)$ & $8 / 118(7)$ \\
\hline Diabetes mellitus & $77(90)$ & $9(10)$ & $4 / 77(5)$ & $0 / 9(0)$ \\
\hline Thyroid dysfunction & $32(84)$ & $6(16)$ & $3 / 32(9)$ & $0 / 6(0)$ \\
\hline Atrial fibrillation & $32(58)$ & $23(42)$ & $0 / 32(0)$ & $5 / 23(22)$ \\
\hline Hypertension & $304(81)$ & $73(19)$ & $15 / 304(5)$ & $7 / 73(10)$ \\
\hline
\end{tabular}

${ }^{*}$ Mean corpuscular volume $<80 \mathrm{fl}$ in six participants and $>100 \mathrm{fl}$ in six participants.

nesota codes $8-3-1$ or $8-3-2^{4}$ for atrial fibrillation or flutter; and systolic pressure $>160 \mathrm{~mm} \mathrm{Hg}$ or diastolic pressure $>95 \mathrm{~mm} \mathrm{Hg}$ for hypertension.

Among the 528 participants 38 were known to have anaemia, 77 had diabetes mellitus, 32 had thyroid dysfunction, 32 had atrial fibrillation, and 304 had hypertension (table). We newly identified 118 with anaemia, 9 with diabetes mellitus, 6 with thyroid dysfunction, 23 with atrial fibrillation, and 73 with hypertension (table). Over 90\% of all participants, except for those with newly identified atrial fibrillation, had consulted their general practitioner at least once in the year before the study.

\section{Comment}

Using information from general practitioners and pharmacy records combined with five simple and readily available procedures we have obtained reliable estimates of the prevalence of five common clinical abnormalities in very elderly people. We found a considerable number with previously undetected anaemia and hypertension but fewer with previously undetected thyroid dysfunction, atrial fibrillation, and diabetes mellitus. We have shown that our criteria for anaemia, diabetes mellitus, thyroid dysfunction, and hypertension are adequate for elderly people and can serve as guidelines for clinicians treating older patients. Experienced staff reviewed all automated interpretations and codings of electrocardiograms for atrial fibrillation so we consider that our interpretation of this abnormality is completely reliable. In conclusion, we have shown that it is feasible to use these investigative procedures in an elderly population to provide important quantitative information for future discussions on screening elderly people.

Contributors: AJMdC,JG, and RGJW designed the study. AJMdC and YKOT performed the statistical analysis. PWM analysed ECG recordings. All authors interpreted the results and contributed to writing the paper. AJMdC is guarantor for the study.

Funding: None

Competing interests: None declared.

Ethical approval: The Medical Ethical Committee of the Leiden University Medical Centre approved the study.

1 Von Faber M, Bootsma-van der Wiel A, van Exel E, Gussekloo J, Lagaay $\mathrm{AM}$, van Dongen E, et al. Successful aging in the oldest old. Who can be characterized as successfully aged? Arch Intern Med 2001;161:2694-700.

2 World Health Organization. Guidelines for ATC classification and DDD assignment. Oslo: WHO Collaborating Centre for Drugs Statistics Methodology, 1996.

Izaks GJ, Westendorp RGJ, Knook DL. The definition of anaemia in olde persons. JAMA 1999;18:714-7.

Macfarlane PW, Latif S. Automated serial ECG comparison based on the Minnesota code. J Electrocardiol 1996;29(suppl):29-34.

5 Topol EJ, Califf RM, Isner, J, Prystowsky EN, Serruys PW, Swain JL, et al. Textbook of cardiovascular medicine. Philadelphia: Lippincott-Raven, 1998. (Accepted 10 June 2003)

\title{
Longevity and carrying the C282Y mutation for haemochromatosis on the HFE gene: case control study of 492 French centenarians
}

Hélène Coppin, M Bensaid, S Fruchon, N Borot, H Blanché, M P Roth

Unité de

Physiopathologie Cellulaire et

Moléculaire, CNRS

UPR 2163, CHU

Purpan, 31059

Toulouse Cedex 3,

France

Hélène Coppin

research scientist

M Bensaid

PhD student

S Fruchon

PhD student

$\mathrm{N}$ Borot

research scientist

MP Roth

research scientist

continued over

BMJ 2003;327:132-3
Hereditary haemochromatosis is a common autosomal recessive disorder of iron metabolism. Most patients are homozygous for a C282Y mutation in the HFE gene. This mutation is frequent in northern Europe, where one in five to ten people are carriers. People who are heterozygous for the C282Y mutation have slightly but significantly higher values for serum iron and transferrin saturation and are less likely to have anaemia because of iron deficiency. ${ }^{12}$

Iron promotes the generation of free radicals, which leads to mutagenesis, atherosclerosis, inflammation, and bacterial growth. Therefore, genotypes that increase the concentrations of iron for transport and storage may be associated with an increased risk for common diseases, such as cancers and cardiovascular diseases, and for inflammatory and infectious conditions. Other studies, which investigated the associations of C282Y heterozygosity with morbidity, found conflicting results, and consensus has not been reached about whether $\mathrm{C} 282 \mathrm{Y}$ is associated with the development of extrahepatic cancers, coronary heart disease, or diabetes. ${ }^{12}$

We hypothesised that people who are heterozygous for the C282Y mutation are under-represented in a centenarian population because many would have died younger from life threatening diseases which are more prevalent in C282Y heterozygotes.

\section{Participants, methods, and results}

We recruited 492 French centenarians, who consented personally, through the Chronos Project at the Foundation Jean Dausset (Centre d'Etude du Polymor- 
Genotypes at the C282Y mutation site in centenarians and controls*

\begin{tabular}{|c|c|c|c|c|c|c|c|c|}
\hline \multirow[b]{3}{*}{ Genotype } & \multicolumn{4}{|c|}{ No of centenarians (\%) } & \multicolumn{4}{|c|}{ No of controls (\%) } \\
\hline & \multicolumn{3}{|c|}{ Observed } & \multirow[b]{2}{*}{ Total expected $\dagger$} & \multicolumn{3}{|c|}{ Observed } & \multirow[b]{2}{*}{ Total expected $\nmid$} \\
\hline & Men & Women & Total & & Men & Women & Total & \\
\hline WT/WT & 77 & 369 & $446(90.7)$ & 445.15 & 78 & 371 & $449(91.3)$ & 449.0 \\
\hline WT/C282Y & 3 & 41 & $44(8.9)$ & 45.68 & 2 & 40 & $42(8.5)$ & 42.02 \\
\hline$\overline{\mathrm{C} 282 \mathrm{Y} / \mathrm{C} 282 \mathrm{Y}}$ & 0 & 2 & $2(0.4)$ & 1.17 & 0 & 1 & $1(0.2)$ & 0.98 \\
\hline
\end{tabular}

${ }^{*}$ The lower frequency of C282Y carriers in men (3.8\% in centenarians $v 2.5 \%$ in controls) compared with females $(10.4 \%$ v $9.9 \%)$ reflects the uneven distribution of the geographic origin in men and women; of the centenarians, $26 \%$ of women and only $10 \%$ of men were born in the northwest of France, where the C282Y allele is much more common than in any other region. This underlines the necessity of a careful matching in case control studies to avoid the risk of finding spurious associations solely due to population stratification. †According to Hardy-Weinberg equilibrium; expected and observed numbers do not differ significantly.

phisme Humain). ${ }^{3}$ The 80 men and 412 women were white, born in France, and more than 99 (mean 103.1) years old on the day we collected blood. We selected 492 controls from unrelated white people who were born in France and matched the centenarians for sex and geographic origin (mean age 51.2 years). The treating doctor completed a detailed health questionnaire and the results of the last blood test were collected for each person. We amplified the HFE gene using a polymerase chain reaction, and we detected the C282Y mutation using denaturing high performance liquid chromatography on a Wave DNA Fragment Analysis System (Transgenomic, Crewe). ${ }^{4}$

The centenarians included 44 heterozygotes and the matched controls contained 42 heterozygotes; the difference is not statistically significant even taking sex into account (table). The odds ratio of becoming centenarian when carrying the C282Y mutation was 1.08 (95\% confidence interval 0.70 to 1.66 ), encompassing the value of 1 expected under the null hypothesis.

We found two homozygotes for the C282Y mutation among the centenarians and one among the controls; all were women. None had been treated by phlebotomy and none had been diagnosed with haemochromatosis. Distributions of the genotypes in the control and in the centenarian groups satisfied Hardy-Weinberg equilibrium, which is not in favour of a selection against either homozygotes or heterozygotes for the C282Y mutation among centenarians.

\section{Comment}

Complications thought to be associated with heterozygosity for the C282Y mutation of the HFE gene, such as carcinomas or cardiovascular diseases, did not deplete a centenarian population of heterozygotes for C282Y. Heterozygosity for C282Y does not seem to be a risk factor for these common life threatening conditions.
Finding people over 99 years old who are homozygous for the C282Y mutation and still alive without treatment confirms that clinical penetrance in homozygotes for the $\mathrm{C} 282 \mathrm{Y}$ mutation is incomplete, as recently suggested in a study of more than 41000 people in California. ${ }^{5}$ That longevity is not compromised by either being a heterozygous or homozygous carrier of the C282Y mutation precludes the recommendation of population genetic testing for C282Y. Rather, alternative strategies should be implemented to improve early detection of hereditary haemochromatosis in people with abnormal indexes of iron metabolism and their close relatives.

Contributors: HC and MPR conceived and designed the study, analysed the data, and wrote the manuscript. $\mathrm{MB}, \mathrm{SF}$, and $\mathrm{NB}$ helped with genotypings and analyses. $\mathrm{HB}$ is in charge of the Chronos Project at the Foundation Jean Dausset-CEPH and provided the centenarian and control DNAs used for this study. All authors approved the final version of the manuscript. MPR is guarantor.

Funding: European Union (QLK6-CT-1999-02237).

Competing interests: None declared.

Ethical approval: Ethics committee (CCPPRB) of the Hospital Saint-Antoine, Paris.

1 Fuchs J, Podda M, Packer L, Kaufmann R. Morbidity risk in HFE associated hereditary hemochromatosis C282Y heterozygotes. Toxicology 2002:180:169-81.

2 Worwood M. HFE Mutations as risk factors in disease. Best Pract Res Clin Haematol 2002;15:295-314.

3 Blanche H, Cabanne L, Sahbatou M, Thomas G. A study of French centenarians: are ACE and APOE associated with longevity? C R Acad Sci III 2001;324:129-35.

4 Fruchon S, Bensaid M, Borot N, Roth MP, Coppin H. Use of denaturing HPLC and a heteroduplex generator to detect the HFE C282Y mutation associated with genetic hemochromatosis. Clin Chem 2003;49:822-4.

5 Beutler E, Felitti VJ, Koziol JA, Ho NJ, Gelbart T. Penetrance of 845G--> A (C282Y) HFE hereditary haemochromatosis mutation in the USA. Lancet 2002;359:211-8.

(Accepted 29 April 2003)
Centre d'Etude du Polymorphisme Humain, Fondation Jean Dausset, 75010 Paris, France

H Blanché research scientist

Correspondence to: M P Roth roth@cict.fr

One hundred years ago

The prolongation of life

Tobacco and snuff

Tobacco is to many persons a means of enjoyment, and is well borne by them, if they take it with moderation; it soothes nervous irritability and makes men often look more contentedly on their troubles. On the other hand excessive smoking is decidedly injurious to the majority of people by affecting the heart, the digestion, the nerves, and the throat. In many cases diminution of the amount of smoking, or taking a milder kind of tobacco, remedies the bad effects; in some, however, the use of tobacco has to be given up entirely.
Snuff is out of fashion at present; but to some people with stuffiness of the nose a pinch taken once or twice a day is useful by rendering the breathing through the nose more easy, and also by maintaining to a certain degree the sense of smell, since it acts by its stimulation as a species of gymnastics on the capillaries of the Schneiderian membrane. Many old doctors maintained that snuff taking was a good practice against some forms of frontal headache and blear eyes, and not without some reason.

(BMJ 1903;ii:1449) 